\title{
La inflación de lo emocional en la actividad publicitaria ¿Constituye un cambio de paradigma?
}

\author{
Felip VIDAL AULADELL ${ }^{1}$ \\ Universidad Complutense de Madrid
}

\begin{abstract}
RESUMEN:
Se propone analizar la intensificación del uso de elementos emocionales y experienciales en la actividad publicitaria como una inflación de lo imaginario en la producción semiótica del signo/mercancía que, a su vez, cabe ubicar en la evolución de la función representativa de la marca por la que ésta pasó de representar el producto a ser el lugar en el que, en una suerte de actividad proyectiva, se representa el sujeto consumidor. Desde esta aproximación, es posible observar cómo, en los últimos años, se ha producido una evolución -y no un cambio de paradigma- en el seno de la denominada publicidad de la significación. Así, una ahora renovada producción semiótica del signo/mercancía viene centrando de modo creciente su atención a la creación de unas marcas cada vez más virtualizadas en las que el valor-que era atribuido, en la publicidad referencial, a las características "intrinsecas" al producto- ha pasado casi exclusivamente a predicarse de la marca/corporación y de la experiencia que su consumo conlleva. Por otra parte, aquella intensificación del uso de elementos emocionales y experienciales ha traído consigo el desarrollo de nuevas estrategias comunicativas que constituyen un conjunto de mecanismos, tanto de densificación de unas marcas cada vez más autorreferenciales y virtualizadas como de invisibilidad u ocultación a los ojos de los consumidores de la lógica de la producción semiótica del signo/mercancía, que consisten en una triple figuración del mismo: a) en distintos soportes y superficies, b) en el sujeto consumidor, y c) por medio de su narrativización.
\end{abstract}

PALABRAS CLAVE: Marketing; marca; consumo; identidad; signo/mercancía.

TITLE: The inflation of the emotional in advertising,. Does it represent a change of paradigm?

\section{ABSTRACT:}

The aim of this article is to analyze the increasing use of emotional and experiential elements in advertising as an inflation of the imaginary in the semiotic production of sign/merchandise which, in turn, can be placed in the evolution of the representative function of the brand, having moved from representing the product itself on to becoming the place where, in a sort of projective activity, the individual consumer is represented. From this approach, we can see how, in recent years, there has been an evolution -rather than a change of paradigm- within the so-called advertising of meaning. Thus, a now renewed semiotics production of sign/merchandise is increasingly drawing its attention to the creation of brands more and more virtualized in which the value -attributed in referential advertising to the inherent features of the product- has become nearly exclusively predicated about the brand/corporation and the experience its consumptions entails. Moreover, the increasing use of emotional and experiential elements has led to the development of new communication strategies which form a set of mechanisms, working both as a way to densify these more and more self-referential, virtualized brands as well as an element of invisibility or hiding from the consumers' eyes of the logic of the semiotics production of sign/merchandise, which consist of a triple figuration of

1 Doctorando en el Departamento de Comunicación Audiovisual y Publicidad I de la Facultad de Ciencias de la Información de la Universidad Complutense de Madrid (UCM). Licenciado en Derecho (UdG) y en Filosofía (UNED). Diploma de Estudios Avanzados (DEA) en el Departamento de Historia de la Filosofía, Estética y Filosofía de la Cultura de la Universidad de Barcelona (UB). E.mail: felipvidal@eartvic.net. 
the same: a) on different supports and surfaces, b) in the individual consumer, and c) by means of its narrativization.

KEY WORDS: Marketing; brand; consumption; identity; sign/merchandise.

\section{Planteamiento y objetivos}

Si atendemos a la literatura de marketing ${ }^{2}$ y gestión de marcas publicada en los dos últimos decenios pudiera parecer que hemos asistido, en la actividad publicitaria actual, a la puesta en escena - sin que tal vez sea ahora relevante precisar una posible distinción entre uno y otro- de un paradigma emocional y/o de un paradigma experiencial. Así, por ejemplo, Marc Gobé presenta su célebre Branding emocio$n a l^{3}$, tal y como reza el subtítulo, como el nuevo paradigma para conectar las marcas con las personas.

Por otra parte, afirmar que «all marketing in the future will be based on some form of consumer experience [...] The mass marketing paradigm is over ${ }^{4}$, nos induce rápidamente a pensar, como corolario, que el marketing experiencial constituye el nuevo paradigma que ha venido a sustituir a otro paradigma anterior. La misma idea se encuentra contenida -ya que si bien no utiliza la expresión "nuevo paradigma" explícitamente, bien podría ésta sustituirse por el término "revolución" que sí aparece reiteradamente en el texto- en el ya canónico Experiential Marketing de Bernd H. Schmitt cuando afirma que:

We are in the middle of a revolution. A revolution that will render the principles and models of traditional marketing obsolete. A revolution that will change the face of marketing forever. A revolution that will replace traditional feature-and-benefit marketing with experiential marketing ${ }^{5}$.

Como se tratará de exponer, ambos "supuestos" o "posibles" paradigmas no constituyen, sin embargo, sino meras técnicas fundamentadas en el uso de unas categorías que, tomadas así sin mayor precisión, son de por sí vacías e insuficientemente significativas para una teoría de publicidad. De este modo, aparece com-

2 Se utiliza el término marketing, siguiendo a Antonio Caro, para designar el cúmulo de herramientas empresariales características del emergente capitalismo de consumo y de entre las que forma parte la publicidad. Desde esta perspectiva, la producción semiótica, teniendo por referente no al producto sino a la marca, engloba y da sentido al conjunto de actividades empresariales incluidas en el marketing-mix. CARO, A. (2002): «Del valor de consumo a la corporación como valor», Sphera Publica. Revista de Ciencias Sociales y de la Comunicación, 2, Murcia, Universidad Católica San Antonio, 65-79.

3 GobÉ, M. (2005): Branding emocional. El nuevo paradigma para conectar las marcas emocionalmente con las personas. Barcelona, Divine Egg.

2 Lenderman, M. (2006): Experience The Message. How Experiential Marketing Is Changing the Brand World, New York, Carroll \& Graf Publishers, 15.

5 снмітт, B. H. (1999): Experiential Marketing, New York, The Free Press, 3. 
pletamente acertada la observación de James B. Twitchell en relación con la profusión de títulos y recetarios sobre esta cuestión. Así:

It seems that every publisher of business books has a ready supply of Brand-this and Brand-that titles: A New Brand World, Emotional Branding, Brand Warfare, Strategic Brand Management, Be Your Own Brand, Brand Leadership, Brand New, Brand Asset Management, Managing Brand Equity, Building Strong Brands, The 22 Immutable Laws of Branding, and so on. Most of the three thousand business books published each year are written for people in business who want to make money and who think branding is just the ticket. They may be right, but, as is often the case, the big money is not in doing it but in writing the book about it ${ }^{6}$.

Sin embargo, y más allá de esta observación, la crítica contenida en estas páginas tratará de dar un paso más en la dirección de mostrar en qué sentido es inadecuado -o, cuando menos, incompleto- considerar como tales aquellos "supuestos" paradigmas -al menos en el modo como son expuestos desde la literatura de marketing y gestión de marcas- a la hora de realizar un abordaje teórico al fenómeno publicitario. Además, pretenderá poner de manifiesto la necesidad de llevar a cabo a la vez que ensayar una aproximación más comprehensiva y global a un hecho incuestionable como es el importante protagonismo otorgado a los elementos emocionales y experienciales en la actividad publicitaria actual.

Para ello, se caracterizará la intensificación en el uso de elementos emocionales y experienciales en la actividad publicitaria actual como una inflación de lo imaginario en la producción semiótica del signo/mercancía que tiene lugar en el marco de la evolución de la función representativa de la marca que ha dado lugar a una creciente importancia de la actividad proyectiva del sujeto consumidor en la actividad publicitaria. En este contexto, como se verá, la emoción, como ingrediente fundamental de la publicidad de la significación, ha devenido el lugar donde reside el valor tanto de unas marcas virtualizadas como de unos productos desmaterializados.

A partir de aquí, y más allá de la forma concreta cómo se representan y conectan las emociones con el consumo y la actividad publicitaria, se observará cómo dichos elementos emocionales y experienciales, a la vez que participan en un proceso de maximización de lo imaginario que corre paralelo a la minimización de la densidad material del signo/mercancía, vehiculan y configuran la actividad publicitaria mediante varios procesos que, en cuanto mecanismos de densificación en los que la actividad proyectiva del sujeto consumidor adquiere un protagonismo fundamental -y que consisten en la figuración del signo/mercancía: a) en distintos

6 Twitchell, J. B. (2005): Branded Nation, New York, Simon \& Schuster, 1.

7 Se utilizan aquí los conceptos producción semiótica y signo/mercancía en el sentido elaborado por Antonio Caro. Véase, por ejemplo, CARO, A. (1993): La publicidad de la significación (marco, concepto y taxonomía), Madrid, Universidad Complutense de Madrid, 61 y ss. O, más recientemente, CARO, A. (2010): Comprender la publicidad, Barcelona, Universitat Ramon Llull, 190 y ss. 
soportes y superficies sean o no típicamente publicitarias, b) en el sujeto consumidor y c) por medio de su narrativización - pretenden otorgar o recuperar, en lo que no deja de ser un pliegue sin profundidad, una cierta entidad corpórea a unas marcas cada vez más virtualizadas ${ }^{8}$.

Todos estos mecanismos de densificación del signo/mercancía pueden enmarcarse, en primer lugar, en el proceso que se ha propuesto denominar tridimensionalización del signo/mercancía ${ }^{9}$ y de acuerdo al que éste ha dejado de ser un contenido imaginario únicamente representado visualmente para desparramarse por multitud de medios, soportes, prácticas, estrategias y técnicas. Además, en segundo lugar, a la vez que configuran una actividad publicitaria actual caracterizada por la intensificación del uso de elementos emocionales y experienciales, no son sino, por otra parte, un modo de tratar de mantener oculta a los ojos de los consumidores la lógica de la producción semiótica -es decir, de lograr su invisibilidad- soslayando el hecho de que el imaginario contenido en un signo/mercancía que, vaciado de su materialidad, no refiere a otra cosa que a sí mismo.

Aunque resulte difícil abordar en estas páginas esta argumentación en toda su extensión - por lo que varias cuestiones apuntadas quedarán pendientes de desarrollo ulteriorr- cabe señalar que es en el marco del aparato conceptual sucintamente delineado en los párrafos anteriores desde dónde parece posible -e, incluso, tal vez idóneo- efectuar una aproximación al fenómeno publicitario como síntoma de los cambios estructurales que tienen lugar en el modo de producción social y cultural. De este modo, los nuevos desarrollos en marketing y publicidad pueden ser observados como resultado de la propia lógica y evolución del sistema económico, con el objetivo de comprender y teorizar la actividad publicitaria actual ahondando en la dirección propuesta por Antonio Caro en el sentido de:

[...] comprender intelectualmente la publicidad, en cuanto componente imprescindible de esa comprehensión global del fenómeno publicitario que ha de implicar, a su vez, la aprehensión en términos activos y, por consiguiente, movilizadores de esa impregnación por la publicidad que experimentamos día a día; ya que de esa comprehensión depende en buena medida, como no me canso de repetir, la de la sociedad en su conjunto de la que la publicidad constituye un factor de primera línea, así como el impulso de las potencialidades de transformación que laten en su seno ${ }^{10}$.

8 La marca y la publicidad, como no podría ser de otro modo, participan y forman parte del actual contexto de virtualización del capitalismo tardío en el que lo financiero y lo especulativo se han impuesto definitivamente sobre la economía productiva. Como advertide Antonio Caro, «hoy nos encontramos en una fase de virtualización de la marca [ya que] ésta adopta un estatus gaseoso que la transmuta en mero signo capaz de existir al margen de cualquier contenido material» CARO, A. (2009): «Una fase decisiva en la evolución de la publicidad: la transición del producto a la marca», Pensar la Publicidad. Revista Internacional de Investigaciones Publicitarias. , 3 (2), 109-132 (114).

9 Vidal Auladell, F. (2011): «La producción semiótica ante la significatización de la economía (O ¿cómo lograr una publicidad efectiva en la era del capitalismo virtual», Pensar la publicidad. Revista Internacional de Investigaciones Publicitarias, 5 (1), 75-97.

10 CARO, A. Comprender la publicidad, 75. 


\section{La inflación de lo imaginario en la producción semiótica del signo/mercancía}

Existe una abundante bibliografía dedicada al desarrollo de la importancia de los contenidos emocionales y experienciales a la hora de generar un valor añadido para la marca/corporación con el objetivo de aumentar su eficacia en el contexto de mercados saturados y ante consumidores maduros, lo que da buena muestra del reconocimiento unánime de la importancia fundamental que se atribuye a nivel práctico a dichos aspectos.

De acuerdo con estos textos, y teniendo en cuenta que «una marca debe ser una combinación de atractivos físicos, lógicos y emocionales que se complementen» ${ }^{11}$, se advierte que «la marca debe enamorar a los consumidores, al tiempo que inspira y participa de sus emociones más profundas» ${ }^{12}$. La publicidad, por su parte, «necesita emocionarle [al consumidor], crearle sentimientos, hacerle sentir, divertirle, enamorarle y sólo así será eficaz, porque los aspectos emocionales son los que nos impulsan a la acción» ${ }^{13}$.

De este modo, la estrategia publicitaria debe dirigirse hacia establecer un vínculo "afectivo" entre la marca y el consumidor ${ }^{14}$ que deberá ser adecuadamente gestionado puesto que «las emociones pueden crear o destruir una marca y su impacto es bastante duradero, así que hay que manejarlas cuidadosamente cuando se crea una estrategia de marca» ${ }^{15}$.

A modo de ejemplo puede observarse, en dos conocidos spots con un elevado contenido emocional como son el célebre ¿Te gusta conducir? de BMW -Fig. 1 y 2-, o el más reciente spot de Coca-Cola -Fig. 3 a $8-$ en el que tienen lugar el encuentro entre un bebé recién nacido y el hombre más longevo del estado español, cómo se incide en ambos casos en la parte emocional del espectador sin hacer referencia de modo directo a las características del producto sino que se trata de vincular éste a sensaciones y emociones.

\footnotetext{
11 ARnOld, D. (1992): Cómo gestionar una marca, Barcelona, Parramón, 38.

12 LÓPEZ VÁzqUEZ, B. (2007): Publicidad emocional. Estrategias creativas. Madrid, ESIC, 38.

13 Martín ReQuero, M. I. (2006): «Creativos publicitarios, creadores de sensaciones», en ALvarado López, M. y Martín Requero, M. I. (Coords.), Publicidad y cultura, Sevilla, Comunicación Social, 94-128 (126).

${ }_{14}$ RoBerTs, K. (2006): Lovemarks. El futuro más allá de las marcas, Barcelona, Empresa Activa.

15 GoBé, M. Branding emocional, 242.
} 
Fig.1 BMW. «¿Te gusta conducir?»(1)

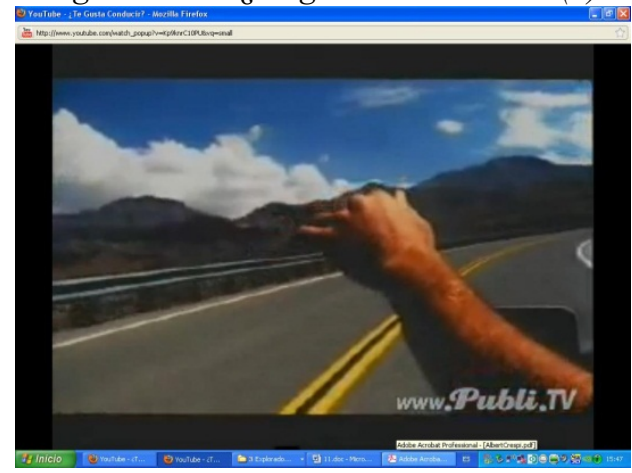

Fig. 3 COCA COLA. «Esta historia es real» (1)

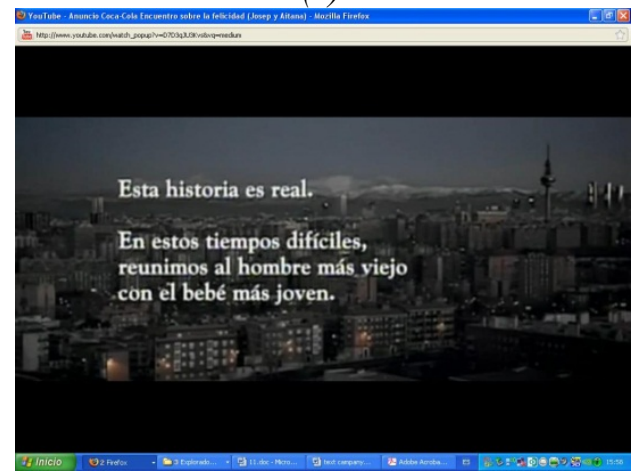

Fig. 5 COCA COLA. «Esta historia es real» (3)

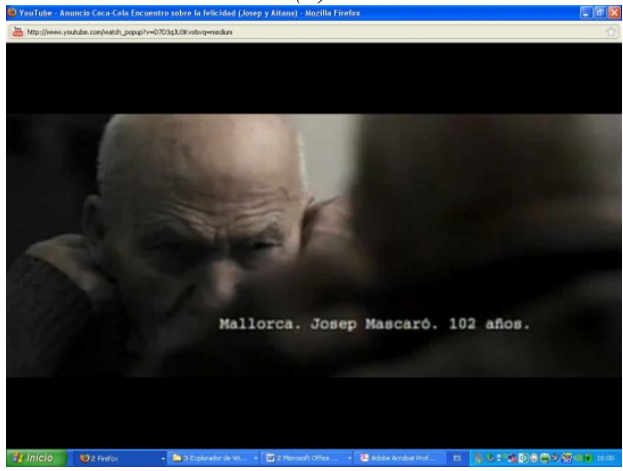

Fig.2 BMW. «¿Te gusta conducir?» (2)

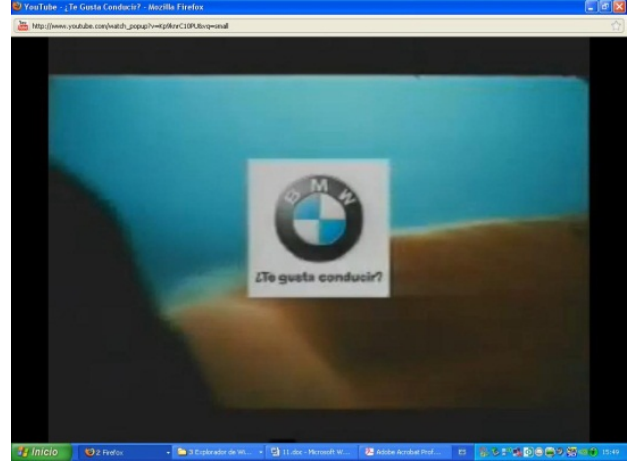

Fig. 4 COCA COLA, «Esta historia es real» (2)

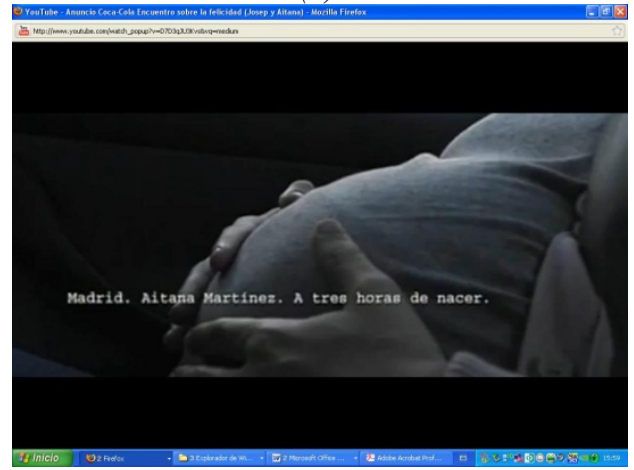

Fig. 6 COCA COLA. «Esta historia es real» (4)

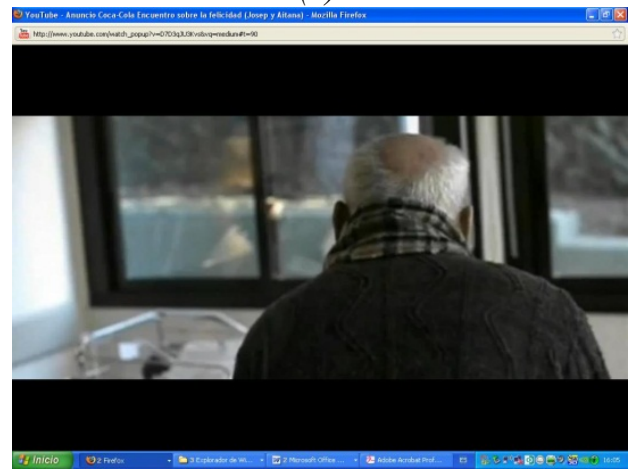


Fig. 7 COCA COLA. «Esta historia es real»

(5)

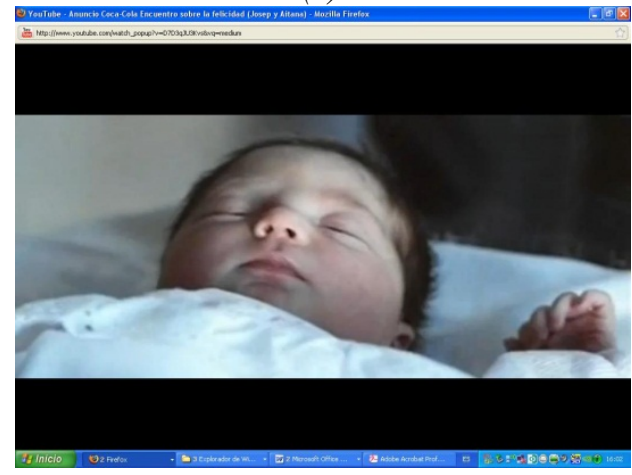

Fig. 8 COCA COLA. «Esta historia es real»

(6)

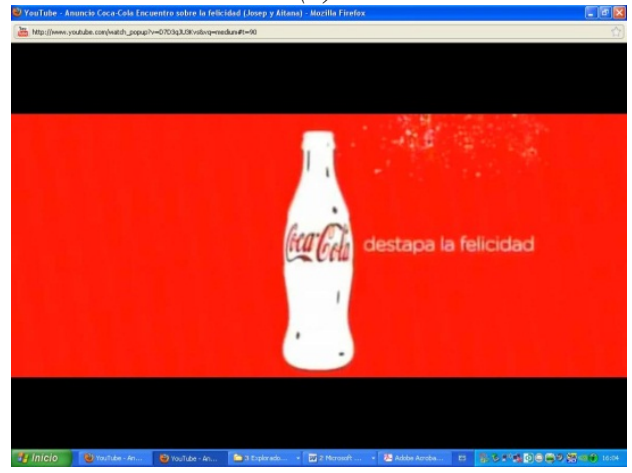

A partir de estas premisas, que alcanzan no sólo el branding o la publicidad sino también el diseño de productos -dónde los aspectos emocionales han pasado a ocupar la centralidad de que antes gozaba la usabilidad ${ }^{16}$ - se articulan, como puede sospecharse, un buen número de técnicas y estrategias concretas a aplicar en la práctica empresarial que frecuentemente son recogidas y narradas a modo de recetas para el éxito en un gran número de títulos que nutren los catálogos de las editoriales.

Sería fácil dar por supuesto entonces que existe lo que podríamos denominar tal y como en muchas ocasiones la propia literatura se encarga de promover - un paradigma emocional y/o experiencial que viene rigiendo la actividad publicitaria desde hace ya unos años. Sin embargo, esta abundancia de recursos bibliográficos no logra eliminar la sospecha de que el ámbito al que refieren estos factores emocionales y experienciales, considerados de capital importancia para una actividad publicitaria eficaz, tal vez no sean ni unos conceptos obvios ni se hallen clara y precisamente delimitados, de modo ni dan cuenta ni explican satisfactoriamente, tanto desde un punto de vista teórico como tampoco desde un punto de vista práctico, el supuesto alcance de su eficacia aunque, claro está, contribuyan a ella.

Otra cosa bien distinta, y que no viene a objetar lo apuntado en el párrafo anterior, es que haya que reconocer, desde un punto de vista práctico, el hecho de que los elementos emocionales han devenido fundamentales no únicamente en la comunica-

16 Destacan, en este sentido, las aportaciones de Donald A. Norman, quien propuso en El diseño emocional un modelo para comprender el modo cómo se produce el impacto que ejercen las emociones en el consumidor. Asimismo, como él mismo advierte: «[...] en la década de 1980, cuando escribí el libro The Design of Everyday Things, no tuve en cuenta las emociones. En aquellas páginas abordé los temas de la utilidad y la usabilidad, de la función y de la forma, todo ello de un modo lógico y desapasionado [...]. Pero ahora, en este nuevo libro, he cambiado de opinión [...]. Hoy, en nuestra condición de científicos, comprendemos lo importantes y valiosas que son las emociones en la vida cotidiana. No hay duda de que la utilidad y la usabilidad son importantes, pero privados de diversión y placer, de alegría y entusiasmo y, en efecto, también de inquietud y rabia, de miedo e ira, nuestra existencia sería incompleta» (NormAn, D. A. (2005): El diseño emocional, Barcelona, Paidós, 23). 
ción publicitaria sino también en el marketing en general. Y tratar de establecer una relación emocional con el consumidor - de modo que se pueda afirmar que «las vidas de ambos han quedado enlazadas como sí sus vidas fueran de personas» ${ }^{17}-$ es quizá unos de los principales aspectos que contribuyen al éxito empresarial.

La importancia de la presencia de estos elementos emocionales y experienciales tal vez resida, en primer lugar, en el hecho de que permiten establecer una relación entre empresario y consumidor mediante una consumer experience que ha venido a paliar las carencias que la teoría del posicionamiento presenta en la actualidad. Así:

[...] cuando Al Ries y Jack Trout elaboraron la teoría del posicionamiento en su libro Positioning en el año 1969, no tuvieron en cuenta al consumidor de la manera en que hoy lo entendemos. Algo lógico teniendo en cuenta que en esos años todo giraba alrededor de los productos, el mercado y la competencia. Las propuestas de Ries y Trout iban encaminadas a encontrar un nicho donde encajar el producto y sus valores diferenciales. [...] cuarenta años después, esa idea del posicionamiento no es suficiente para estar a la altura de los nuevos mercados y, sobre todo, de los nuevos consumidores. [a partir de estas premisas, prosigue Medina] Es preciso renovar el posicionamiento de la empresa y de sus marcas basándose en las nuevas coordenadas del consumer experience ${ }^{18}$.

Pero además, en segundo lugar y desde un punto de vista más global, cabe observar cómo la presencia de elementos emocionales y experienciales en la actividad publicitaria actual remite a la relación entre la actividad publicitaria y el contexto social y económico en el que el consumo consiste no tanto en adquirir una propiedad sino el derecho de acceso a una experiencia ${ }^{19}$. Así, se afirma que:

La publicidad actual, se sitúa en el contexto que le corresponde, en esta sociedad de la información y del conocimiento, y teniendo en cuenta las tendencias actuales, ya no habla de productos, ni siquiera de marcas, habla de la vida y de lo que le preocupa al ser humano: sus relaciones, sus aspiraciones, sus éxitos, sus certezas, sus incertidumbres, sus anhelos y sus vivencias ${ }^{20}$.

No es de extrañar, ante tal panorama, la abundancia de textos de gestión empresarial, marketing ${ }^{21}$ y diseño ${ }^{22}$ que presentan el término experiencia, al igual

\footnotetext{
17 NAvarro Gutiérrez C. (2007): Creatividad publicitaria eficaz, Madrid, ESIC, 165.

18 Medina, A. (2010): Bye, bye, marketing. Del poder del mercado al poder del consumidor, Madrid, Pirámide, 154.

19 En esta dirección, véase Pine, B. J. y GiLmORE, J. H.. (1999): The Experience Economy, Boston, Harvard Business School Press, y RifKIN, J (2002): La era del acceso. Paidós, Madrid.

20 Martín Requero, M. I. y Cruz Alvarado López, M. C. (2007): «Prólogo», en Martín ReQUero, M. I. y CRUZ Alvarado López, M. C. Nuevas tendencias en la publicidad del siglo XXI, Sevilla, Comunicación Social, 7-13 (9).

21 Véase, además de los ejemplos que se van citando esparcidos en estas páginas, LENDERMAN, M. y SÁNCHEZ, R. (2008): Marketing experiencial. La revolución de las marcas, Madrid, ESIC.
} 
como se advirtió con el los aspectos emocionales, ya desde su mismo título. Asimismo, tampoco sorprende su reiterada utilización en el texto de todo tipo de piezas de comunicación publicitaria ${ }^{23}$. Así, como se puede observar en las Fig. 9 a 16, el término experiencia es frecuentemente utilizado en la publicidad de todo tipo de productos y en distintas acepciones.

Fig. 9 HOTELES NUÑEZ Y NAVARRO - «Experiencias NN»

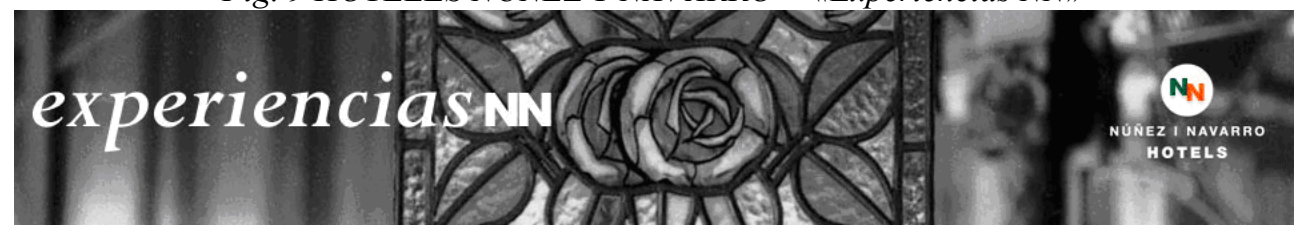

Fig. 10 SONY BRAVIA - «Una experiencia única en $46^{\prime \prime}$
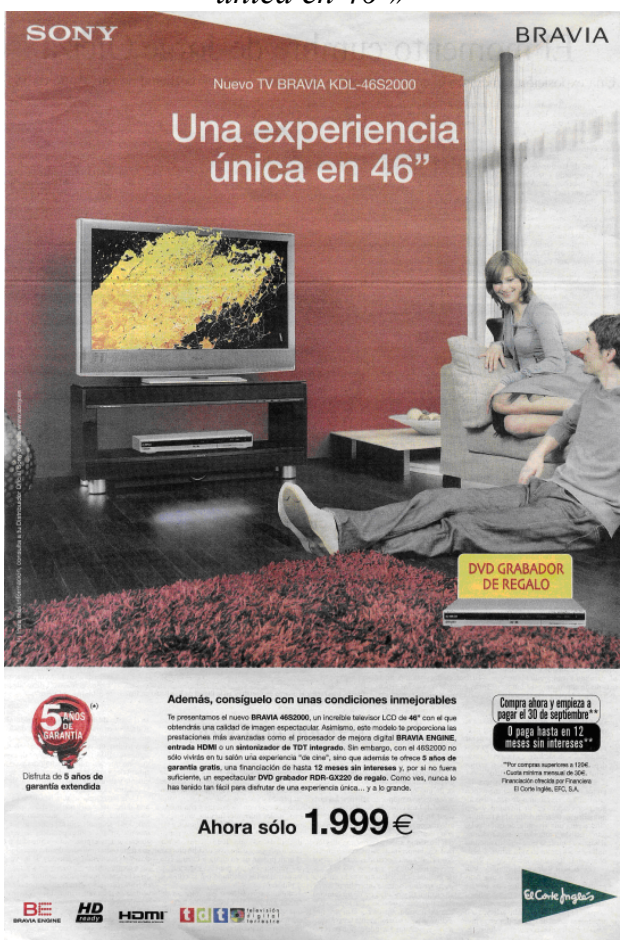

Fig. 11 LEÓN - «Una experiencia artística $y$ cultural»

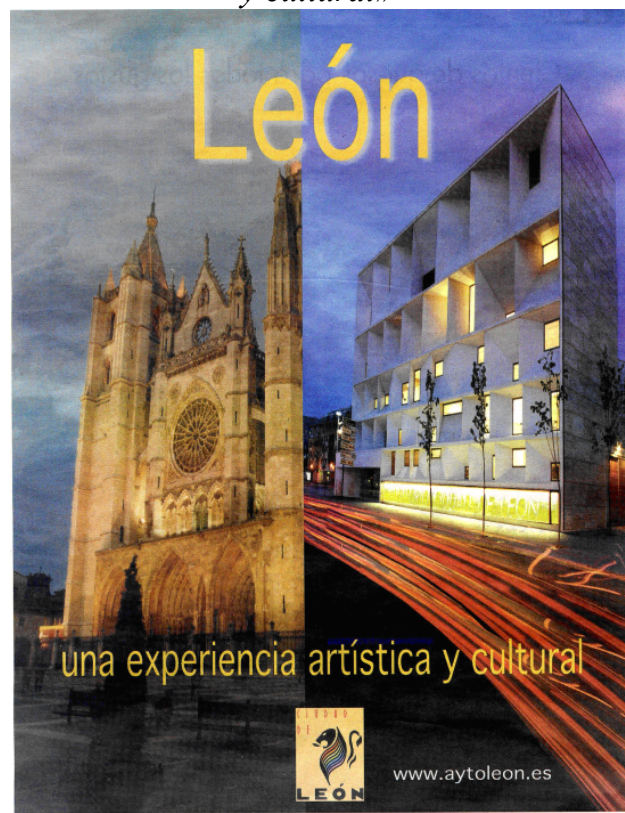

22 Press, M. y COOPER, R. (2009): El diseño como experiencia. El papel del diseño y los diseñadores en el siglo XXI, Barcelona, Gustavo Gili.

${ }^{23}$ Un análisis de esta cuestión puede encontrarse en Vidal Auladell, F. (2008): «Diseño y comunicación. Construyendo identidades mediante experiencias», en PÉREZ-AMAT, R., NUÑEZ, S., García, A. (COORDS), Comunicación, identidad y género. Vol. I, Fragua, Madrid, 226-236. 
Fig. 12 - CADILLAC - "Vive la experiencia Cadillac con el nuevo SRX»

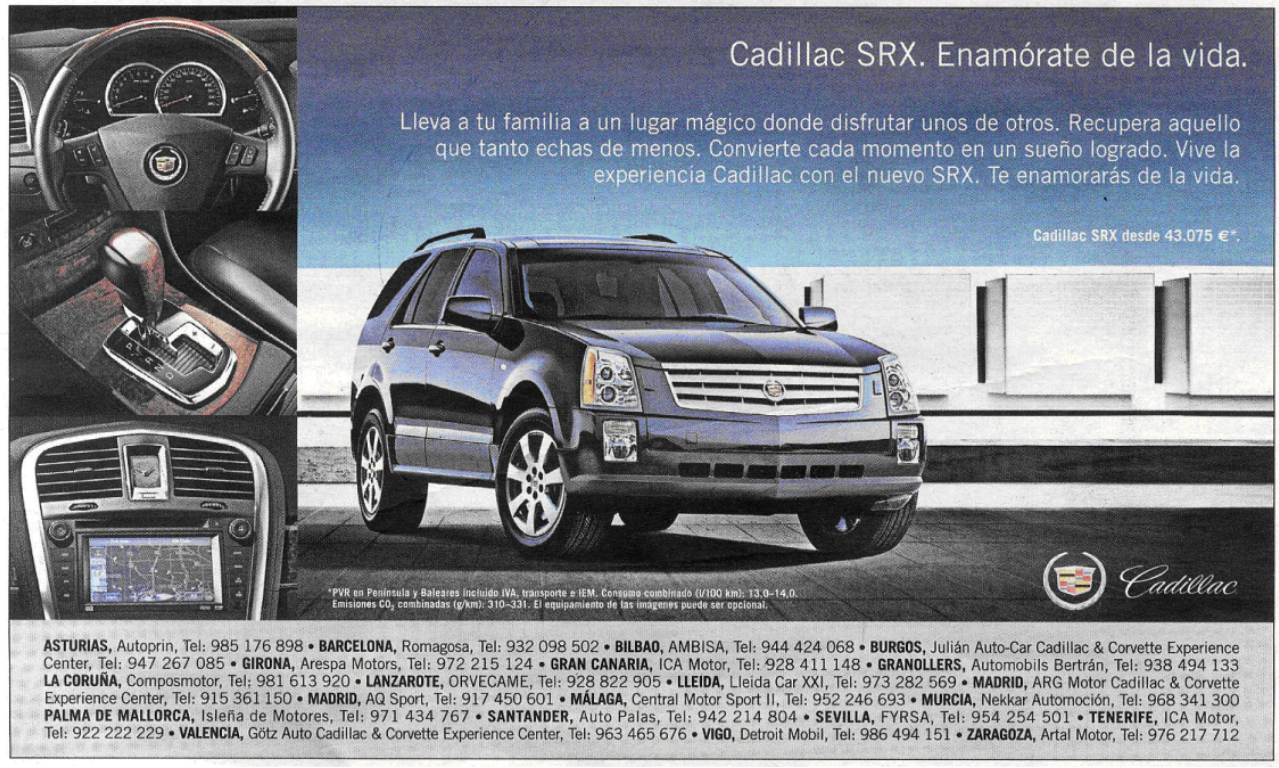

Fig. 13 - SAN MIGUEL. «Mi experiencia»

(1)

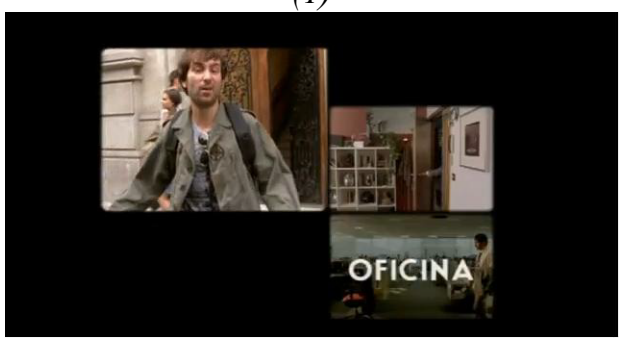

Fig. 15 - SAN MIGUEL - «Mi experiencia» (3)

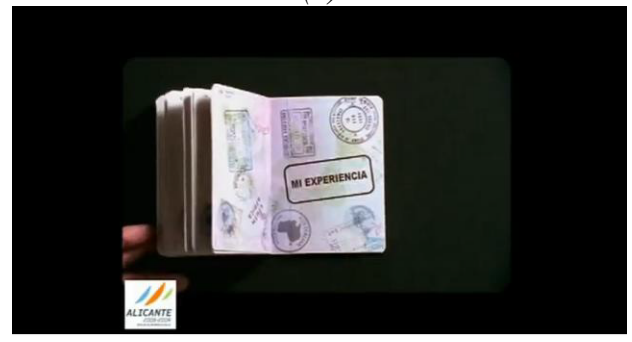

Fig. 14- SAN MIGUEL. «Mi experiencia»

(2)

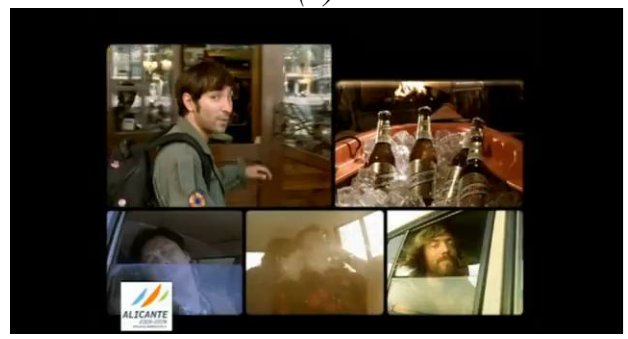

Fig. 16 - SAN MIGUEL - «Mi experiencia»

(4)

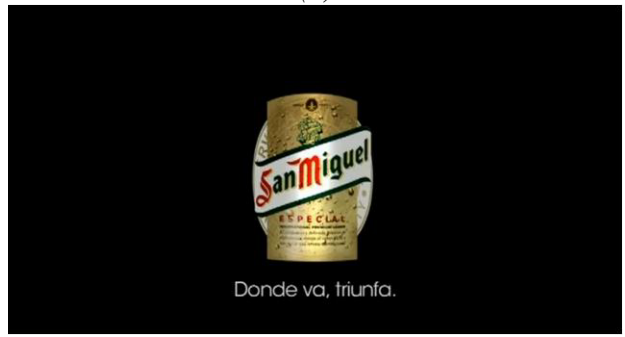


Por todo ello tal vez podría afirmarse, en definitiva, que la intensificación en el uso de elementos emocionales y experienciales en la actividad publicitaria actual - que no es sino, dicho en otros términos, una inflación de lo imaginario en la producción semiótica del signo/mercancía- puede ser analizada, además de como una moda o tendencia, como un síntoma que refleja los cambios estructurales que tienen lugar en el modo de producción social y cultural. En este sentido, dicha intensificación o inflación podría representar un paso más en la tendencia hacia la desmaterialización del producto, en el contexto de la financiarización resultado de la significatización de la economía que ha dado lugar al paso hacia una renovada producción semiótica característica en el contexto de la virtualización del capitalismo financiero, en la que se ha producido una virtualización de la marca de modo que el valor que anteriormente se atribuía a las características "intrinsecas" del producto han pasado a predicarse de la marca/corporación y a la experiencia que su consumo conlleva.

\section{Evolución de la función representativa de la marca: del producto al consu- midor}

La aparición de los "supuestos" paradigmas emocional y/o experiencial a los que se viene haciendo referencia deben situarse en el seno de un proceso de capital importancia - puesto que constituye la condición de posibilidad para la virtualización de la marca y su posterior representación en vivencia y consecuente colonización- que ha tenido lugar en la evolución histórica de la marca: el desplazamiento del énfasis, en la actividad representativa de la marca, del objeto marcado hacia el sujeto consumidor.

Tal y como Wally Olins puso ya puesto de manifiesto de un modo a la par sintético y preciso:

Hubo un tiempo en que las marcas eran simples artículos domésticos: jabón, té, detergente, betún para el calzado y demás artículos cotidianos insulsos que simplemente se usaban y se reponían. La marca era un símbolo de consistencia. En una época de adulteración y falta de confianza en el producto, y de fluctuaciones de precio imprevisibles, la marca significaba calidad, cantidad y precio constante. La imagen de marca proyectaba y sostenía el producto. En la actualidad, todo esto es completamente diferente y las marcas se han convertido en el elemento dominante. Hoy, las características funcionales de los productos no se cuestionan y, aunque las marcas siguen girando en torno a la imagen, ya no proyectan sólo su imagen, sino también la nuestra. Hoy el branding tiene que ver con la participación y la asociación, la demostración externa y visible de las inclinaciones y las elecciones privadas y personales de cada uno ${ }^{24}$.

24 Olins, W. (2003): Brand. Las marcas según Wally Olins, Madrid, Turner, 16. 
Así, si bien en un primer momento la marca «proyectaba y sostenía el producto» $-\mathrm{o}$, dicho de otro modo, el producto era representado en la marca- sucede actualmente que las marcas «ya no proyectan sólo su imagen, sino también la nuestra», de modo que han asumido la función de mostrar y visibilizar $\mathrm{y}$, en definitiva, representar $\mathrm{o}$, mejor dicho, representarse o proyectarse el sujeto consumidor. Véase, a modo de ejemplo, las Fig. 17 y 18, donde la marca representa al producto y sus efectos en el consumidor, mientras que en las Fig. 19 y 20 el sujeto consumidor es representado en la marca mediante un producto que lo singulariza.

Fig. 17 - TÓNICO ORIENTAL

«Exquisita preparación para conservar, restaurar y embellecer el cabello. Extirpa la caspa, fortalece el cráneo y limpia y perfuma la cabeza»

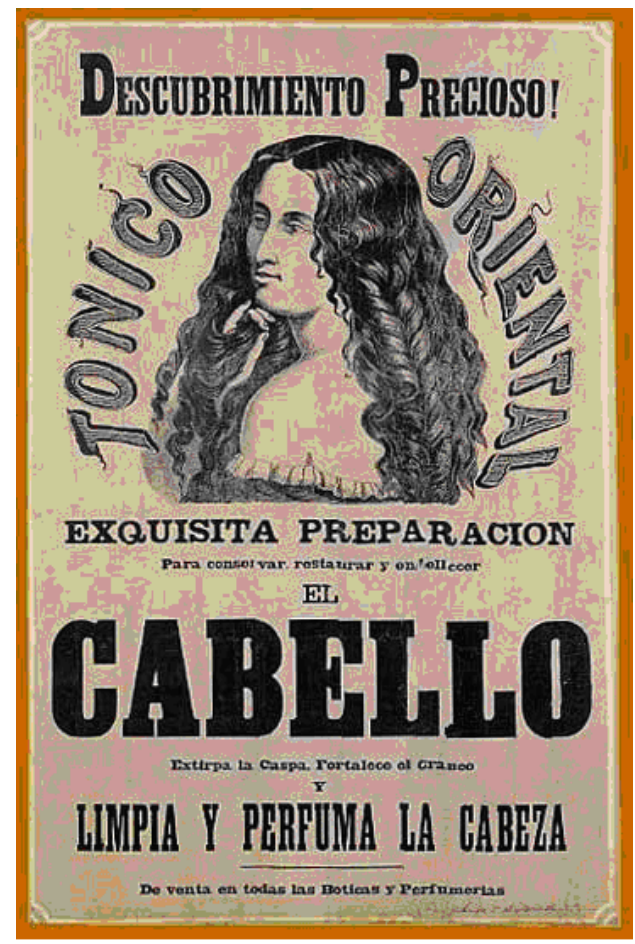

Fig. 18 - CHOCOLATES DE MATÍAS

\section{LÓPEZ}

«Antes de tomar el chocolate de López ... después de tomar el chocolate de López»

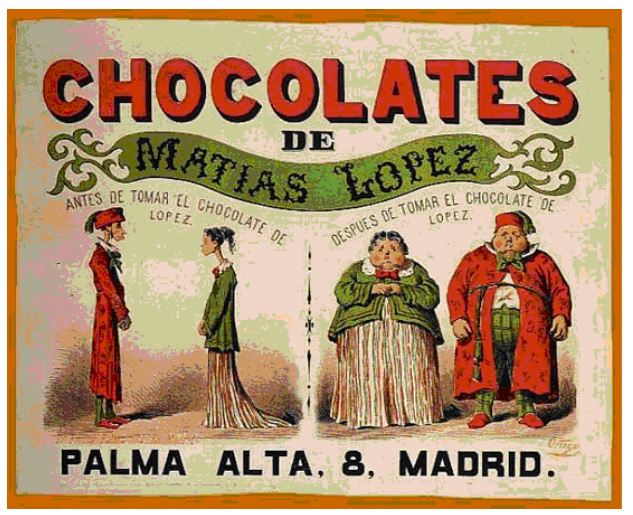


Fig. $19-$ COLUMBIA

«Tu nueva piel sin riesgo de rechazo»

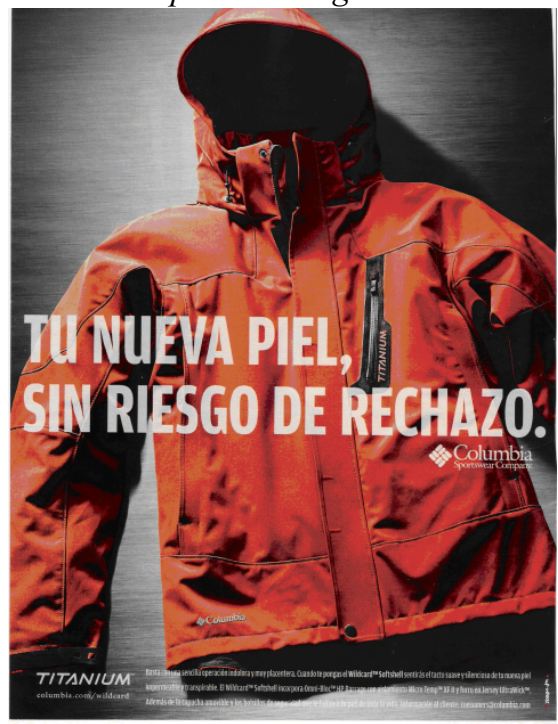

Fig. 20-TAG HEUER

«What are you made of?»

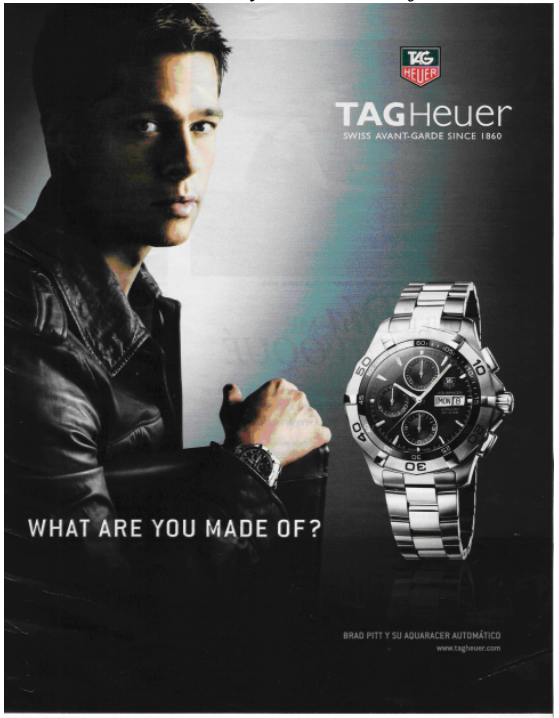

La creciente importancia de esta actividad proyectiva así como el haber situado e intensificado, como eje central de la práctica publicitaria habitual, el recurso a los elementos emocionales y/o experienciales, ha traído consigo importantes consecuencias de carácter práctico en la construcción de las marcas y sus imaginarios $-\mathrm{O}$, dicho de otro modo, para la producción semiótica del signo/mercancía-. Concretamente, es interesante observar cómo la gestión empresarial de la marca perseguirá vehicular la actividad proyectiva ${ }^{25}$ del sujeto consumidor mediante el recurso a argumentos o atributos emocionales con el objetivo de lograr no sólo que aquél se proyecte en la marca, sino que se lleve a cabo del modo mas eficiente posible su adhesión experiencial al mundo imaginario la misma.

Esta adhesión que trata de lograr la corporación mediante la actividad publicitaria se ha ido configurando con el tiempo como algo distinto a «la idea de que el consumo de masas se rija exclusivamente por el proceso de distinción y diferenciación clásica» ${ }^{26}$. Ya que, si bien es cierto que los productos que se consumen son significantes sociales y signos de aspiración social, el consumo se ha vuelto cada vez más un acto relacionado con la autonomía individual e, incluso, con la constitución de la identidad. Pareciera, pues, que las aportaciones de Veblen ${ }^{27}$ o Bor-

25 Para Joan Costa, «lo que hace la imago de la marca es [...] En síntesis, que la imago permita la proyección del yo deseante en ella: nuestra autoimago» (CostA, J. (2004): La imagen de marca. Un fenómeno social, Barcelona, Paidós, 196).

26 Lipovetsky, G. (1990): El imperio de lo efimero, Barcelona, Anagrama, 161.

27 Veblen, T. (1974): Teoría de la clase ociosa, México, Fondo de Cultura Económica. 
dieu $^{28}$ no agotan las posibilidades de este campo de análisis, sino que sus modelos interpretativos basados en la estratificación y la distinción han dejado paso a otros que esgrimen conceptos como, por ejemplo, la «vivencia emocional» ${ }^{29}$.

Así, si bien lo marcado con un modo de ser y una experiencia ya no es tanto el producto como el consumidor, de modo que, como observa Twitchell para la marca Levi's pero que podría hacerse extensivo a la inmensa mayoría de las otras marcas:

[...] a Century ago the Levi's brand was a way to display what are called in marketing the "features and benefits" of a machine-made fabric: denim. The brand was literally stamped on both the packing boxes and the pants. The brand denoted and connoted: it said, "this is from Levi Strauss \& Co., it is Levi's denim, and it means that Levi's is rugged." Later the brand appeared as that big label for all the world to see, right there on you hip, a symbol. By extension, the brand became more than a promise of experience; it became the experience itself: You are rugged. Levi's was not just on your hip, it became hip, just as you do when you wear Levi's ${ }^{30}$.

Cabría añadir, además, que las innovaciones tecnológicas han posibilitado en la actualidad que el sujeto consumidor devenga destinatario y a su vez partícipe en la actividad publicitaria y desarrolle si cabe una mayor actividad proyectiva mediante la creación de contenidos generados por el usuario (user generated content) o la participación en microsites. Así, por medio de estas u otras técnicas, tal y como se ejemplifica en la Fig. 21, se pretende que el consumidor tome parte activa en la construcción tanto del propio discurso publicitario como, en ocasiones, del propio producto que posteriormente adquirirá, a la vez que pase a formar parte de una supuesta comunidad de consumidores deviniendo, con todo ello, partner de la marca/corporación mediante su adhesión experiencial a la misma.

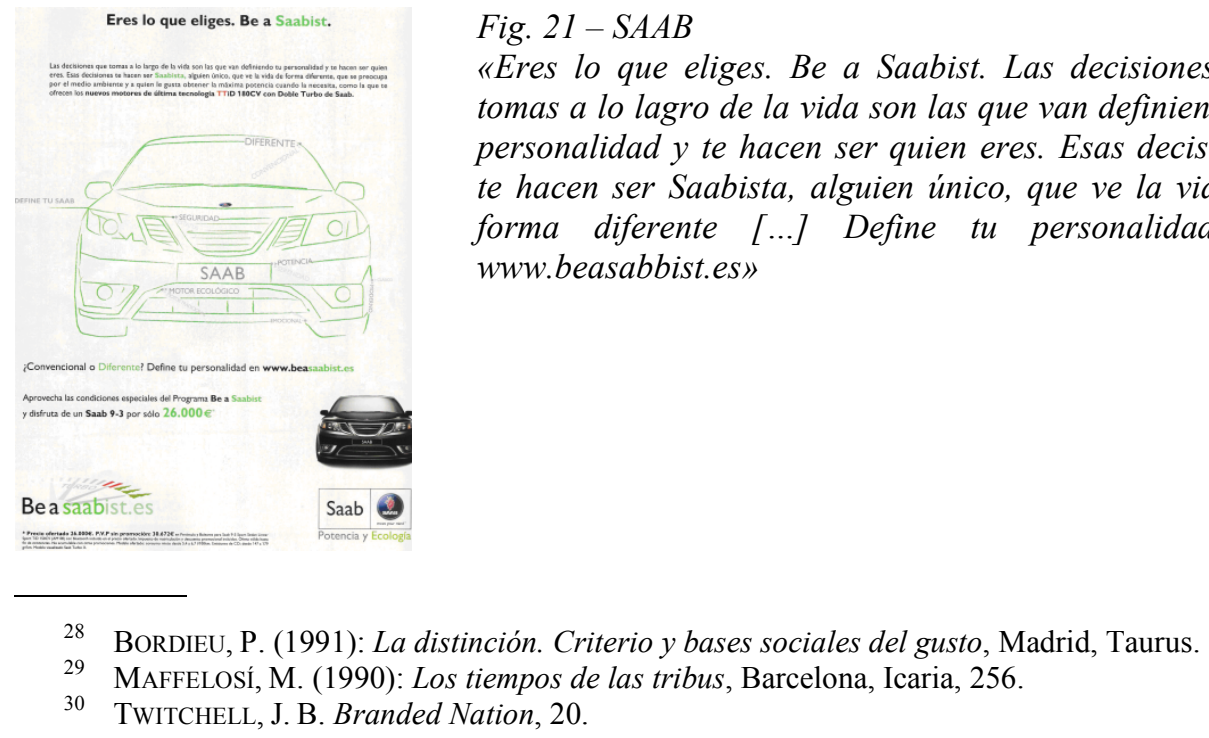




\section{La emoción como lugar del valor en la publicidad de la significación}

De acuerdo con lo expuesto hasta ahora, sin ser completamente novedosa la utilización de elementos emocionales y experienciales en la actividad publicitaria, sí que es posible observar en la actualidad una intensificación de su utilización. En este sentido, resulta interesante contextualizar la evolución de la función representativa de la marca hacia la prosecución de la adhesión experiencial, tal y como ha sido esbozada en la sección anterior - y siguiendo la distinción propuesta por Antonio Caro entre publicidad referencial y publicidad de la significación ${ }^{31}$ - en el marco de los cambios experimentados por la publicidad de la significación y al compás de la creciente virtualización de la marca/corporación que ha ido experimentando.

De acuerdo con Antonio Caro, la publicidad de la significación, que es la propia del capitalismo de consumo o del signo/mercancía, puede definirse del siguiente modo:

[...] es la que, más que a-nunciar, e-nuncia. La publicidad que ya no tiene como referencia un producto o una entidad preexistente que hay que dar básicamente a conocer, sino una marca (un signo, en definitiva) a la que hay que dotar de una significación específica. La publicidad que crea dicha significación (y, en definitiva, la marca-signo que está en su base) en la medida que la comunica. La publicidad que añade, por consiguiente, a su función comunicativa una función propiamente ontológica. Y la que, como resultado de esta transformación, ya no se sitúa (como en el caso de la publicidad referencial) en un lugar intermedio entre la producción y el consumo, sino que pasa a formar parte de la propia producción cumpliendo en su seno (junto con otras actividades derivadas de la misma o relacionadas con ella) la tarea de conferir una significación virtual (esto es: no materializable al margen de la propia escenificación publicitaria) a la marca que ocupa el lugar que antes correspondía al producto, con el resultado de reducir a la insignificancia su materialidad $^{32}$.

Por otra parte, es interesante observar cómo, en dicha publicidad:

31 Esta clasificación representa un desarrollo de la planteada por Jesús Ibáñez, de acuerdo a la cual cabría distinguir entre una publicidad referencial y una publicidad estructural (IBAÑEZ, J. (1994): Por una sociología de la vida cotidiana, Madrid, s. XXI, 233-234).

32 CARO, A. (1994): La publicidad que vivimos, Madrid, Celeste Eresma, 120. Por el contrario, la publicidad referencial, que es descrita como la propia del capitalismo de producción decimonónico, «es la que todo el mundo entiende por publicidad. La que anuncia. La que hace referencia a entidades (productos, servicios, espectáculos) externas y anteriores a la propia publicidad. La que se propone dar a conocer esos productos o entidades; y, además de darlos a conocer, diferenciarlos, argumentar a favor de su adquisición, encomiarlos, exaltarlos; hasta comunicar de ellos (siempre sobre la base de su realidad antecedente y de las características que materialmente los definen) una imagen capaz de hacerlos inconfundibles en la mente de su eventual consumidor y preferibles a cualquiera de sus competidores» (CARO, A. La publicidad que vivimos, 120). En relación con esta clasificación puede consultarse asimismo: CARO, A. La publicidad de la significación (marco, concepto y taxonomía), 9296. 
[...] los recursos emocionales se imponen claramente sobre los racionales, los signos icónicos priman ampliamente sobre los verbales y el discurso retórico dirigido a la persuasión del destinatario, propio de la publicidad referencial, es sustituido por la seducción y fascinación que provoca la signicidad imaginaria de la marca mostrada en su estado más puro ${ }^{33}$.

Estas dos citas nos ponen sobre aviso de dos características de la publicidad de la significación. Es decir, tanto de la importancia y centralidad de los factores emocionales como de la minimización de la materialidad del producto en relación con la maximización de lo imaginario que tenía lugar en la producción semiótica del signo/mercancía y que se ha visto acrecentada en el seno de una renovada producción semiótica que persigue -en su cometido de tratar de mantener la ilusión referencial que permita sostener el carácter semiótico de la marca- la adhesión experiencial del consumidor a su mundo imaginario.

Así, la publicidad de la significación sería aquella en la que, de modo coherente con el devenir del propio sistema económico y productivo ${ }^{34}$, el principal ingrediente de su producción - como ejemplifica el modo cómo se vienen concibiendo las marcas más innovadoras ${ }^{35}$ - no versa sobre artefactos materiales sino acerca de contenidos imaginarios.

Esta importante atención que se otorga a dichos contenidos imaginarios se concreta, como se viene apuntado, en elementos emocionales y/o experienciales, lo que ha traído consigo, como señala Eguizábal, que la publicidad ha dejado de ser un tema mercantil para convertirse en un problema de significación, por lo que «el proceso publicitario se convierte en un proceso semiótico por el cual no son ya los objetos los que se revisten de significado; [sino que] son los conceptos los que se procuran una apariencia, una materialidad ${ }^{36}$. O, dicho de otro modo, el producto es entendido como «la expresión objetual que soporta la marca-signo» ${ }^{37}$, lo que conlleva que «la entidad meramente sígnica de la marca necesita cada vez menos la realidad antecedente del producto» ${ }^{38}$. De este modo, «mientras [que] la publicidad

33 CARO, A. (2008): «La publicidad como núcleo de un imaginario globalizado», en HELLín ORTUÑo, P. A. (coord.). El discurso publicitario contemporáneo. Su relación con lo social, Murcia, Diego Martín, 79-97 (93).

34 Como observa Joan Costa, «el paso del producto a su imagen y del servicio al valor es el itinerario mismo del postindustrialismo; el que va progresivamente de lo material a lo intangible y de lo concreto a lo abstracto» (CosTA, J. La imagen de marca, 162).

35 El análisis que realiza Carlos Scolari de la marca Google, por ejemplo, permite comprobar cómo, en el contexto de una economía que tiende a desmaterializarse, las marcas han devenido pura significación SCOLARI, C. (2005): «Googlemania. Les marques en línia i el cas Google», en CAPRIOTTI, P. La marca corporativa, Vic, Eumo Editorial, 65-90 (88).

36 Eguizábal, R. (2007): Teoría de la publicidad. Cátedra, Madrid, 129.

37 CARo, A. (1998): «La marca como mito», en BlESA, T. (ed). Mitos. Actas del VII Congreso Internacional de la Academia Española de Semiótica, tomo I, Asociación Española de Semiótica y Universidad de Zaragoza, 683-689 (685).

38 CARO, A. La publicidad que vivimos, 142. 
referencial funcionaba al margen de la producción, [...] la publicidad de la significación forma parte sustancial de la producción» ${ }^{39}$.

Es decir, puesto que el concepto de producto es indeslindable de su concreción como tal, la producción semiótica -aunque de como resultado una entidad semiósi$c a-$ consiste en una "auténtica" producción. Sucede, sin embargo, que «la marca del producto es el producto que importa y se porta, se materializa, mientras que el producto se abstrae, se pulveriza ${ }^{40} \mathrm{y}$, como ya advirtió Benjamin: «En el objeto de consumo, la huella de su producción debe quedar olvidada. Debe tener el aspecto de que no ha sido hecho en absoluto $[\ldots]\rangle^{41}$.

La marca, por tanto, queda disponible para su función depositaria, mientras que el producto pasa a ser únicamente el soporte material al que se aplican los contenidos simbólicos resultantes de la producción semiótica. Las Fig. 22 y 23, dónde no existe ninguna referencia que pudiera recordar que el producto ha estado elaborado de algún modo y que responde a unas caraterísticas técnicas y materiales sino que, por el contrario, lo muestra como via de acceso, como "camino" o "viaje" ya sea -así, en abstracto- a "emociones", ya sea al "amor", es decir a la que es tal vez la principal de las emociones.

Y es en este contexto dónde se propone situar la intensificación de la utilización de elementos emocionales y experienciales en la actividad publicitaria. De modo que es en el ámbito delineado por la publicidad de la significación -y no tanto en la aparición de un nuevo paradigma emocional o experiencial- dónde ha tenido lugar, por parte del sujeto consumidor, la deriva desde una incipiente actividad proyectiva hacia su adhesión experiencial al imaginario de la marca, adquiriendo así aquél imaginario inflacionado un valor y un protagonismo cada vez más fundamental.

Asimismo, la importancia de estos contenidos simbólicos a los que se viene aludiendo debe ponerse en relación con «un proceso de desmaterialización que en

39 CARO, A. «La publicidad como núcleo ... », 91.

40 Wortman, A. (2004): «Una aproximación a los nuevos intermediarios culturales del campo publicitario. Individualidades y corporación transnacional», en WORTMAN, A. (ed.) Imágenes publicitarias / nuevos burgueses, Buenos Aires, Prometeo libros, 25-41 (34).

41 Benjamin, W. (2005): Libro de los pasajes. Edición de Rolf Tiedeman, X, 13 a, Madrid, Akal, 681. Como nos recuerda Zizek, «lo que caracteriza al "capitalismo tardío" es la escisión entre la producción de experiencias culturales como tales y su base material (parcialmente invisible), entre el Espectáculo (de experiencia teátrica) y sus mecanismos secretos de puesta en escena. En la percepción ideológica del Primer Mundo de hoy, el trabajo mismo (la labor manual en tanto opuesta a la actividad de producción cultural "simbólica"), y no el sexo, aparece como el sitio de indecencia obscena a ser ocultado del ojo público. Una tradición que se remonta al Rheingold de Wagner y a Metrópolis de Lang, tradición en la que el proceso productivo tiene lugar bajo tierra, en cuevas oscuras, hoy culmina en la "invisibilidad" de los millones de obreros anónimos que trabajan en condiciones infrahumanas en las fábricas del Tercer Mundo desde los Gulags chinos o indonesios hasta las líneas de ensamble en Brasil -Occidente puede permitirse el lujo de hablar de "la clase obrera en desaparición"» (ZizeK, S. (2004): A propósito de Lenin. Política y subjetividad en el capitalismo tardio, Buenos Aires, Atuel/Parusía, 125). 
la actualidad cobra todo su auge, en virtud de la tendencia que lleva a la sustitución del valor de consumo por la corporación capitalista entendida como valor en sí misma ${ }^{42}$. En virtud de este proceso, al pasar el valor que anteriormente se atribuía a las características "intrísencas" del producto a predicarse de la marca/corporación, aquél, por tanto, de algún modo se ha desmaterializado y perdido densidad. $\mathrm{O}$, dicho de otro modo, se ha minimizado la materialidad del producto en relación con la maximización del imaginario en él soportado.

Fig. 22 - SHISEDO

«ZEN. El camino de las emociones, el perfume»

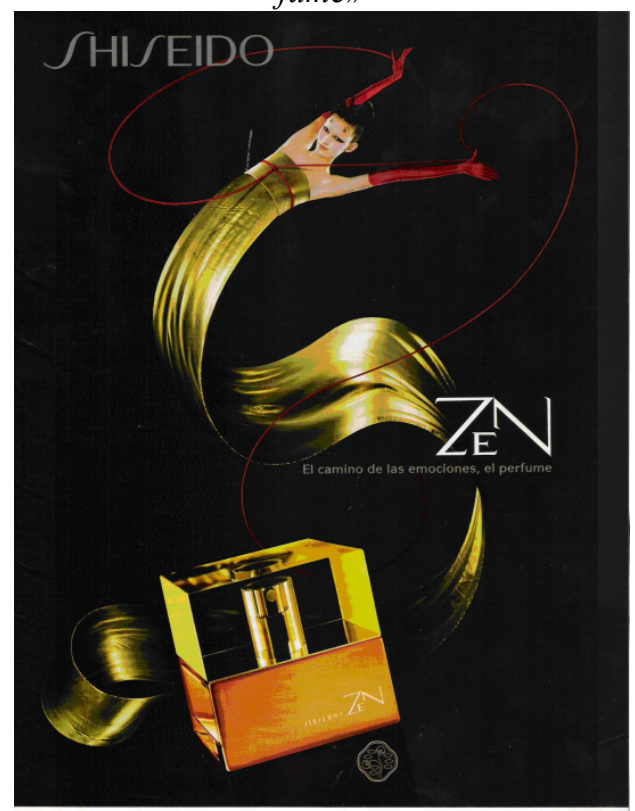

Fig. 23 - LOUIS VUITTON «El amor es indudablemente el mejor de los viajes»

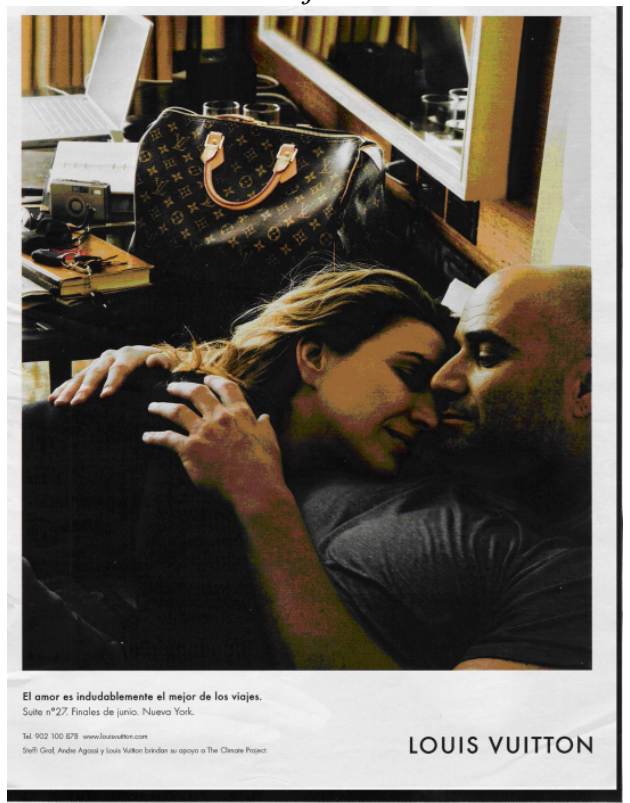

\section{La actividad proyectiva del consumidor: entre los mecanismos de densifica- ción de una marca virtualizada y la invisibilidad de la producción semiótica}

Las observaciones precedentes, que han dado como resultado la presentación de varios conceptos - la función representativa de la marca en el seno de la actividad publicitaria, la actividad proyectiva del sujeto consumidor, etc- deben contextualizarse, en la evolución en la publicidad de la significación y en el seno de una renovada producción semiótica, como contrapunto a la minimización de la materiali-

42 CARO, A. «Del valor de consumo a la corporación como valor», 72. 
dad del producto en relación con la maximización del imaginario en él soportado. De este modo, puede advertirse la importante presencia de los varios mecanismos de densificación e invisibilidad de acuerdo a los que se pretende, por parte de la actividad publicitaria -aunque no sea por supuesto una respuesta consciente e intencionada- tanto otorgar entidad física a un signo/mercancía cada vez más desmaterializado como mantener oculta a los ojos de los consumidores la lógica de la producción semiótica.

Dichos mecanismos -que aquí únicamente serán caracterizados brevemente son: la figuración del signo/mercancía en distintos soportes y superficies sean o no típicamente publicitarias, en el sujeto consumidor y, en tercer lugar, por medio de su narrativización.

De este modo, cabe observar cómo la producción semiótica, en el contexto de la virtualización del capitalismo tardío, busca representar, materializar o, mejor dicho, figurar de algún modo la significación imaginaria del signo/mercancía mediante su plasmación en distintas superficies reales e imaginarias, dando como resultado lo que se propuesto denominar tridimensionalización del signo/mercancía.

Así, en primer lugar, el signo/mercancía ha dejado de ser un contenido imaginario representado visualmente para desparramarse por multitud de medios, soportes, prácticas y técnicas, a la vez que persiguen la que hemos denominado adhesión por la experiencia y que procuran, a su vez, una cierta materialización del signo/mercancía. De este modo, el signo/mercancía no únicamente se representa en la pantalla, sino que adopta forma tridimensional mediante la creación de espacios, ambientes, eventos y formas de comunicación comercial novedosas pasando a construir no sólo ficciones de mundos posibles, sino eventos o acontecimientos e, incluso, auténticos brandscapes que requieren, de un modo u otro, la participación activa del consumidor.

Algunos ejemplos comprenden todas aquellas técnicas, estrategias o herramientas desarrolladas por la más reciente actividad publicitaria y que conllevan nuevas formas de entender el marketing, como son el street marketing, el geomarketing, el engagement marketing, así como una PLV o una publicidad exterior cada vez más interactiva y dinámica (Fig. 24 y 25). De este modo, como sucede en campañas como la denominada "Life is calling", de LEVI'S (Fig. 26) ${ }^{43}$, la marca pasa a ocupar espacios exteriores, interactuando e incentivando a participar en la misma. En esta campaña, algunos de los maniquíes se "fugaron" de los escaparates de sus tiendas, invitando con ello a que quien los encontrara les hiciera una foto y la subiera al sitio web de la campaña, donde ser recibían votaciones de otros participantes optando a varios regalos promocionales.

43 Actualmente ya no se encuentra disponible el sitio web de la campaña (que se realizó entre el 12/03 y el 04/04 de 2010), però sí es posible ver los videos promocionales en el canal LEVI'S SPAIN en Youtube (http://www.youtube.com/user/LevisSpain\#p/u/9/YYb0TPoqxSQ). Web visitada el 08/04/2011. 
Una segunda superfície en la que el signo/mercancía carente de densidad fuera de la que le proporciona la producción semiótica busca corporalizarse o materializarse, es en el sujeto consumidor. Lo singular reside aquí en el hecho de que la marca persigue encarnarse en el sujeto consumidor al proporcionarle a éste los elementos que le permitan representarse en el mundo de la marca/corporación mediante su adhesión experiencial al devenir partner de la misma. Para llevar a cabo este cometido, la actividad publicitaria se orienta estratégicamente hacia el desarrollo de técnicas que persiguen que el consumidor contribuya de modo activo a la producción semiótica con el objetivo de lograr una efectiva identificación y, al fin y al cabo, adhesión del consumidor al mundo imaginario de la marcalcorporación.

Así sucede, por ejemplo, en las campañas en las que se promueve el uso de las tecnologías 2.0 por parte del consumidor genere contenidos comunicativos o para que personalice el producto. Un ejemplo lo encontraríamos en la campaña de la marca $\mathrm{HERO}^{44}$-Fig. 27 - en la que se invita a participar a los consumidores en el sitio web creado al efecto subiendo las recetas de sus platos estrella, pudiendo con ello recibir votos y participando en sorteos y en la edición de un recetario. $\mathrm{O}$ también en la acción de HEINEKEN ${ }^{45}$-Fig. 28 - que permite personalizar una botella de su producto.

El tercer mecanismo de densificación lo constituye, como ya se ha indicado, la narrativización de la marca. Así, como señala C. Salmon, «en menos de quince años el marketing ha pasado del producto al logotipo, y luego del logotipo a la story; de la imagen de marca (brand image) a la historia de marca (brand story)» ${ }^{46}$, lo que podría interpretarse en el sentido de que, una vez transitado de la mercancía al signo/mercancía y una vez virtualizada la marca aún más si cabe, ésta busca volver a adquirir una cierta densidad que le permita sostener -o justificar- algún modo de experiencia que permita fundamentar un vínculo con el sujeto consumidor.

Con este objetivo, la marca trata de singularizarse mediante la construcción de narrativas que frecuentemente requieren la participación activa y del consumidor y, por tanto, su proyección en el imaginario de la marca y, en mayor o menor medida, su adhesión experiencial, a la vez que ejercen de reclamo comunicativo basado en el elemento de reconocimiento por parte de otros consumidores potenciales.

Constituyen dos ejemplos de este mecanismo tanto la campaña BEETLE STORIES $^{47}$-Fig. 29- en la que se invita a participar a los consumidores en el sitio web creado al efecto subiendo las recetas de sus platos estrella, pudiendo con ello recibir votos y participando en sorteos y en la edición de un recetario, como la acción de PAPER MATE ${ }^{48}$-Fig. 30- que, creada en motivo del lanzamiento de su nueva

www.sebuscanrecetascaseras.com. Web visitada el 08/04/2011.

www.heineken.es/home/yourheineken/ Web visitada el 08/04/2011.

SALMON, C. (2008): Storytelling, Barcelona, Península, 57.

$\mathrm{http} / / / \mathrm{www} \cdot$ beetlestories.com/ Web visitada el 08/04/2011.

$\mathrm{http}: / /$ www.creatuhistoriaconpapermate.com/ Web visitada el 08/04/2011.
} 
línea de productos biodegradables, permite a los usuarios participar en la creación del Libro Verde de Paper Mate mediante sus narraciones orientadas hacia el respeto por el medio ambiente y optar así a varios premios.

Estos tres mecanismos de densificación son también, a su vez, técnicas de invisibilidad y no reconocimiento por parte del consumidor del control que ejerce la marca/corporación en la construcción del discurso soportado en el signo/mercancía. Es por ello que suelen trasladar, por mínima que sea, una cierta actividad de la producción semiótica del signo/mercancía al sujeto consumidor para así tratar de legitimar una autenticidad de la experiencia que tiene lugar y de la que el sujeto consumidor participa en un acto de consumo ahora expandido a otros ámbitos y actividades que anteceden al momento de la compra del producto, lo que nos pone sobre aviso de que, en realidad, quizá de lo que se trata es de mercantilizar la experiencia misma en cuanto vivencia.
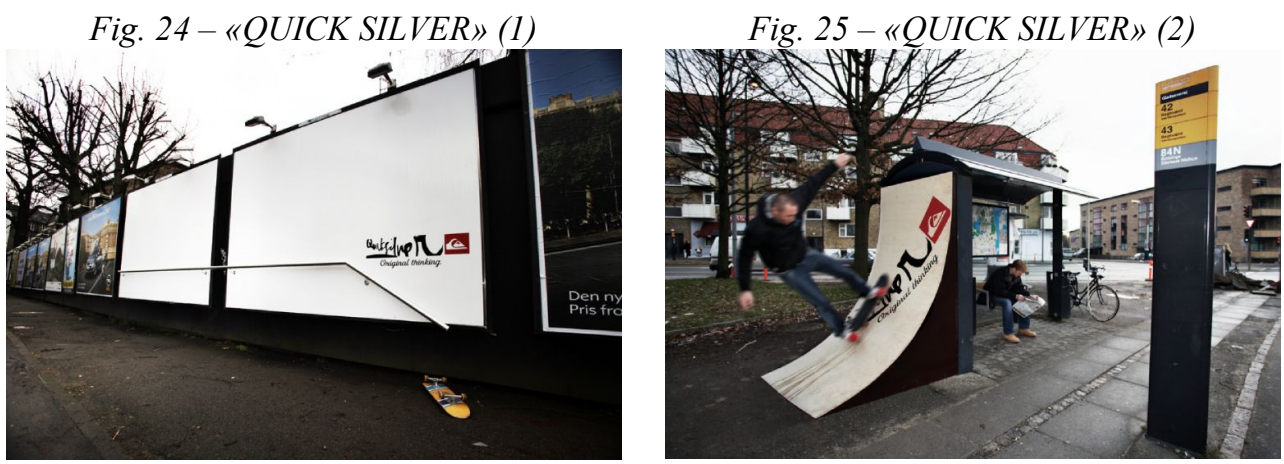

Fig. 26- «LEVI’S “Life's calling»

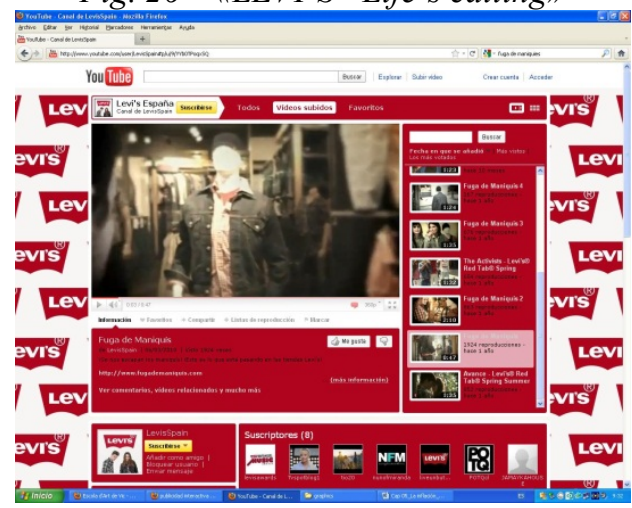

Fig. 27 - HERO «Recetas caseras»

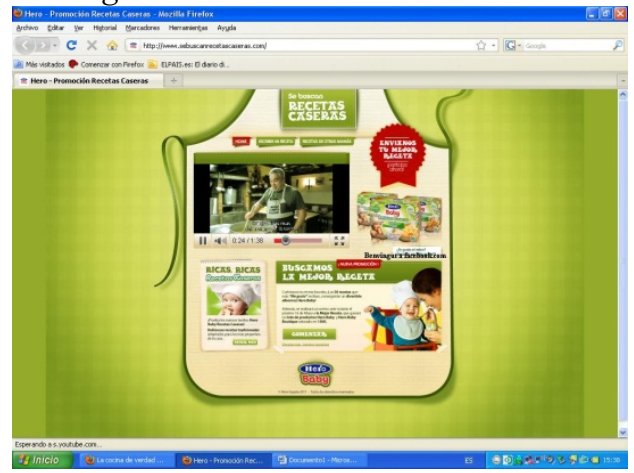


Fig. 28-HEINEKEN «My Heineken»

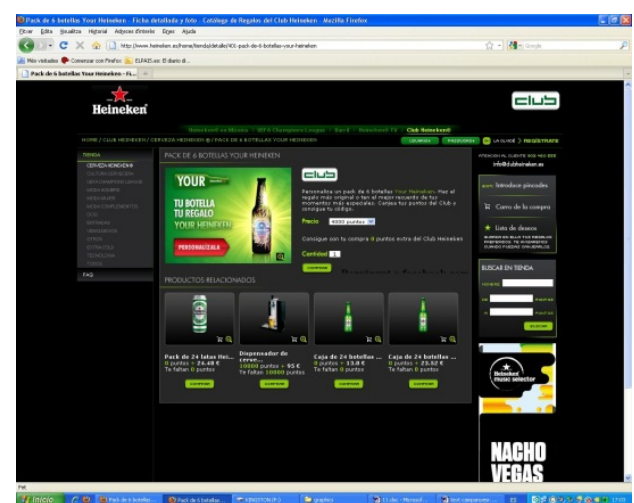

Fig. 29-BEETLE STORIES «Una recopilación de historias vividas junto a un

Beetle»

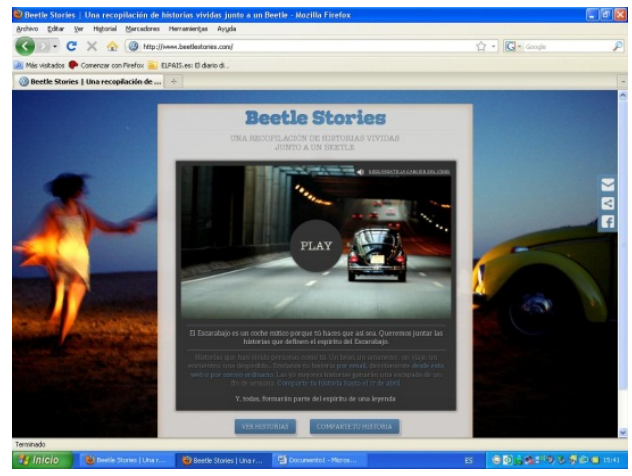

Fig. 30 - PAPER MATE «Crea tu historia con Paper Mate ¿Te atreves a escribir el futuro?»

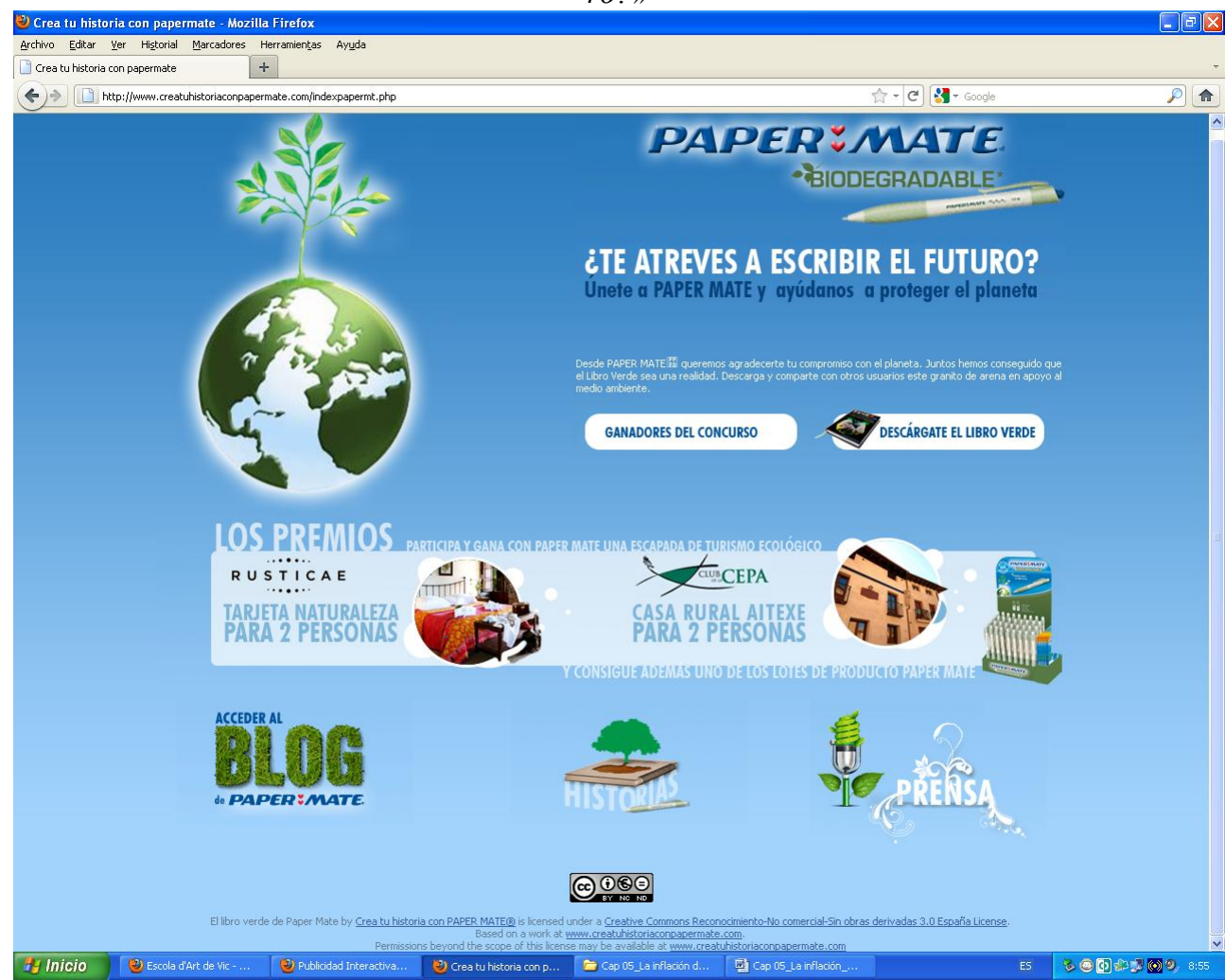




\section{Conclusiones y discusión}

La crítica a la "supuesta" existencia de un paradigma emocional y/o experiencial en el branding y, más en general, en la actividad publicitaria actual, al margen de otros motivos que se podrían argüir y que no se han recogido en estas páginas como son, por ejemplo, la dificultad de discernir a la práctica entre argumentos emocionales y racionales o la puesta en cuestión de su carácter novedoso- se ha dirigido a señalar que la intensificación del uso de elementos emocionales y experienciales ha dado lugar a una inflación de lo emocional que pone de manifiesto una evolución de la denominada publicidad de la significación, que refleja un paso más en la tendencia hacia la desmaterialización del producto y la virtualización de la marca en el contexto de la financiarización y significatización de la economía, lo que da como resultado un proceso en el que tiene lugar la maximización de lo imaginario y la minimización de la materialidad del producto.

Ante esta situación, como se ha expuesto, se puede constatar la aparición de varios mecanismos de densificación del producto e invisibilidad del mecanismo de producción semiótica que dan como resultado una tridimensionalización del signo/mercancía que parece dar cuenta de una tendencia hacia la colonización de toda vivencia que parece haber cumplido, e incluso superado, la afirmación de Debord en el sentido de que:

El espectáculo es el momento en el cual la mercancía alcanza la ocupación total de la vida social. No es únicamente que se haga patente la relación con la mercancía, sino que ya no hay otra cosa más que esa relación: el mundo visible es su mundo ${ }^{49}$.

Sin embargo, cabría añadir, la mercancía - utilizando la terminología de Debord- no sólo ha terminado ciertamente por ocupar o colonizar la vida social, de modo que «el mundo a la vez presente y ausente que el espectáculo hace visible es el mundo de la mercancía que domina toda vivencia» ${ }^{50}$ sino que, además, trata de extenderse hasta colonizar la experiencia en cuanto vivencia.

Dicho de otro modo, una vez colonizado todo lo visible, la actividad publicitaria trata de ser capaz adherir emocionalmente al sujeto para que forme parte activa en la construcción del mundo imaginario de la marca/corporación vinculando emociones, identidad y consumo.

Así, mediante el recurso a unas experiencias completamente mercantilizadas, de tal modo que ha devenido extremadamente difícil discernir éstas de otras tal vez más "auténticas", la experiencia proporcionada por el consumo -como resultado de la adhesión del sujeto consumidor al imaginario de la marca/corporación por medio de su actividad proyectiva - es presentada como el ámbito dónde reside la autenti-

49 Debord, G. (2003): La sociedad del espectáculo, Valencia, Pre-textos, 55.
50 Debord, G. Ibidem, 53. 
cidad vivencial, en lo que se podría atisbar tal vez la expresión sintomática de un cierto contenido o aspiración utópica.

\section{Referencias bibliográficas}

ARNOLD, D. (1992): Cómo gestionar una marca, Barcelona, Parramón.

BENJAMIN, W. (2005): Libro de los pasajes, Madrid, Akal, Bourdieu, P. (1991): La distinción. Criterio y bases sociales del gusto, Madrid, Taurus.

CARO, A. (1993): La publicidad de la significación (marco, concepto y taxonomía), Madrid, Universidad Complutense de Madrid.

- (1994): La publicidad que vivimos, Madrid, Celeste Eresma.

- (1998): «La marca como mito», en BlESA, T. (ed). Mitos. Actas del VII Congreso Internacional de la Academia Española de Semiótica, tomo I, Asociación Española de Semiótica y Universidad de Zaragoza, 683-689.

- (2002): «Del valor de consumo a la corporación como valor», Sphera Publica. Revista de Ciencias Sociales y de la Comunicación, 2, Murcia, Universidad Católica San Antonio, 65-79.

- (2007): «Fundamentos epistemológicos y metodológicos para un estudio científico de la publicidad», Pensar la publicidad. Revista Internacional de Investigaciones Publicitarias, 1 (1), 55-82.

- (2008): «La publicidad como núcleo de un imaginario globalizado», en HELLÍN ORTUÑO, P. A. (coord.). El discurso publicitario contemporáneo. Su relación con lo social, Murcia, Diego Martín, 79-97.

- (2009): «Una fase decisiva en la evolución de la publicidad: la transición del producto a la marca», Pensar la publicidad. Revista Internacional de Investigaciones Publicitarias, 3 (2), 109-132.

- (2010): Comprender la publicidad, Barcelona, Universitat Ramon Llull.

Costa, J. (2004): La imagen de marca. Un fenómeno social, Barcelona, Paidós.

DeBord, G. (2003): La sociedad del espectáculo, Valencia, Pre-textos.

EGUIZÁBAL, R. (2007): Teoría de la publicidad. Cátedra, Madrid.

FeAtherstone, M. (2000): Cultura de consumo y posmodernismo, Buenos Aires, Amorrortu.

GoBÉ, M. (2001): Branding emocional. Barcelona, Divine Egg.

IBAÑEZ, J. (1994): Por una sociología de la vida cotidiana, Madrid, s. XXI.

JAY, M. (2003): La crisis de la experiencia en la era postsubjetiva, Santiago de Chile, Universidad Diego Portales.

Lenderman, M. (2006): Experience The Message. How Experiential Marketing Is Changing the Brand World, New York, Carroll \& Graf Publishers.

LENDERMAN, M. Y SÁNCHEZ, R. (2008): Marketing experiencial. La revolución de las marcas, Madrid, ESIC.

LIPOVETSKY, G. (1990): El imperio de lo efímero, Barcelona, Anagrama.

LÓPEZ VÁZQUEZ, B. (2007): Publicidad emocional. Estrategias creativas. Madrid, ESIC.

MAFFELosí, M. (1990): Los tiempos de las tribus, Barcelona, Icaria. 
MARTÍN REQUERO, M. I. (2006): "Creativos publicitarios, creadores de sensaciones», en Alvarado LóPez, M. Y Martín ReQuero, M. I. (coords.), Publicidad y cultura, Sevilla, Comunicación social, 94-128.

MARTín Requero, M. I. y CRUZ Alvarado LóPez, M. C. (2007): «Prólogo», en Martín Requero, M. I. Y CRUZ Alvarado LóPeZ, M. C. Nuevas tendencias en la publicidad del siglo XXI, Sevilla, Comunicación Social, 7-13.

MedinA, A. (2010): Bye, bye, marketing. Del poder del mercado al poder del consumidor, Madrid, Pirámide.

NAVARro GutiÉRrez C. (2007): Creatividad publicitaria eficaz, Madrid, ESIC.

Norman, D. A. (2005): El diseño emocional, Barcelona, Paidós.

Olins, W. (2003): Brand. Las marcas según Wally Olins, Madrid, Turner.

PINE, B. J. Y GILmore, J. H. (1999): The Experience Economy, Boston, Harvard Business School Press.

Press, M. y COOPER, R. (2009): El diseño como experiencia. El papel del diseño y los diseñadores en el siglo XXI, Barcelona, Gustavo Gili.

RIFKIN, J (2002):. La era del acceso. Paidós, Madrid.

RoBERTS, K. (2006): Lovemarks. El futuro más allá de las marcas, Barcelona, Empresa Activa.

SAlmon, C. (2008): Storytelling, Barcelona, Península.

SchmitT, B. H. (1999): Experiential Marketing, New York, The Free Press.

SCOLARI, C. (2005): «Googlemania. Les marques en línia i el cas Google», en CAPRIOTTI, P. La marca corporativa, Vic, Eumo Editorial, 65-90.

Twitchell, J. B. (2005): Branded Nation, New York, Simon \& Schuster.

VEBLEN, T. (1974): Teoría de la clase ociosa, México, Fondo de Cultura Económica.

Vidal Auladell, F. (2008): «Diseño y comunicación. Construyendo identidades mediante experiencias», en PÉREZ-AMAT, R., NuÑEZ, S., GARCÍA, A. (coords), Comunicación, identidad y género. Vol. I, Fragua, Madrid, 226-236.

- (2011): «La producción semiótica ante la significatización de la economía (O ¿cómo lograr una publicidad efectiva en la era del capitalismo virtual», Pensar la publicidad. Revista Internacional de Investigaciones Publicitarias, 5 (1), 75-97.

WORTMAN, A. (2004): «Una aproximación a los nuevos intermediarios culturales del campo publicitario. Individualidades y corporación transnacional», en WORTMAN, A. Imágenes publicitarias / nuevos burgueses, Buenos Aires, Prometeo libros, 25-41.

ZIZEK, S. (2004): A propósito de Lenin. Política y subjetividad en el capitalismo tardio, Buenos Aires, Atuel/Parusía.

Recibido: 10 de abril de 2012

Aceptado: 5 de julio de 2012 